\title{
Study of heterogeneous suspensions: A new quantitative approach coupling laser granulometry and UV-vis spectrophotometry
}

\author{
Sylvie Bayle ${ }^{\mathrm{a}}$, Nathalie Azéma ${ }^{\mathrm{a}, *}$, Catherine Berho ${ }^{\mathrm{b}}$, Marie-Florence Pouet ${ }^{\mathrm{b}, 1}$, \\ Jose-Marie Lopez-Cuesta ${ }^{a}$, Olivier Thomas ${ }^{\mathrm{b}, 1}$ \\ a Centre des Matériaux de Grande Diffusion, Ecole des Mines d'Alès, 6 avenue de Clavières, 30319 Alès cedex, France \\ b Laboratoire Génie de l'Environnement Industriel, Ecole des Mines d'Alès, 6 avenue de Clavières, 30319 Alès cedex, France
}

\begin{abstract}
The aim of this work is to propose a complementary approach, in order to study heterogeneous fractions from papermaking industries, strongly differing in chemical nature, size and shape of particles. This approach is based on two optical methods: UV-vis spectrophotometry and laser granulometry. Heterogeneity of fractions, especially related to particle size, increases difficulty to perform an analytical approach over a large particle size scale. Methodology is developed on model mixtures in order to highlight limitations, either for a qualitative or a quantitative control, in so far as quantification efficiency could depend on mass transfer phenomena.
\end{abstract}

Keywords: UV-vis spectrophotometry; Laser granulometry; Scattering; Colloids; Suspensions; Quantification

\section{Introduction}

Aqueous suspensions are commonly used in many industries (such as minerals, ceramics, cosmetics, and pulp and paper) and involved in different steps of manufacturing processes (such as final products, intermediates of production and effluents). In addition to separation treatments (filtration, flotation, gravimetric separation, etc.), characterization of disperse media over a wide range of granulometric distribution is necessary in order to optimize and control processes and so to manage final product quality. The range of particle concentration and size are two classical criteria to choose convenient methods in order to study heterogeneous suspensions. Indeed, classical rotational and oscillatory rheometers are inappropriate to characterize low concentration suspensions especially in a quantitative purpose [1].

\footnotetext{
* Corresponding author. Tel.: +33 466785356.

E-mail address: nathalie.azema@ema.fr (N. Azéma).

${ }^{1}$ Observatoire de l'Environnement et du Développement Durable, Université de Sherbrooke, Sherbrooke, Que., Canada J1K 2R1.
}

Optical methods, such as turbidimetry, are often chosen to control suspension quality because they can be used on line and allow a real time monitoring [2]. These methods are based on interactions between a light beam and a particle and are often limited by the fact that scattering is depending on suspension parameters such as concentration (multiple light scattering) and particle properties (optical properties, particle shape and rugosity) [3-6]. For instance, turbidimetry is not able to discriminate chemical nature of particles which is globally considered. Another limitation of optical methods arises from the fact that they are size scale restricted. For instance, low angle light scattering (LALLS) and multi-angle light scattering (MALLS) are suitable for colloidal systems $[7,8]$, turbidimetry can be used in a range of $1-100 \mu \mathrm{m}$ [9] and dynamic light scattering methods are suitable for monodisperse systems and particle sizes up to $0.5 \mu \mathrm{m}$ [10].

Other commonly used optical methods are UV-vis spectrophotometry and laser granulometry. The first one is mainly used in environmental fields, whereas the second one is used for qualitative control of particles size especially for powders. Although study of light and particles interactions have been studied for the development of granulometric 


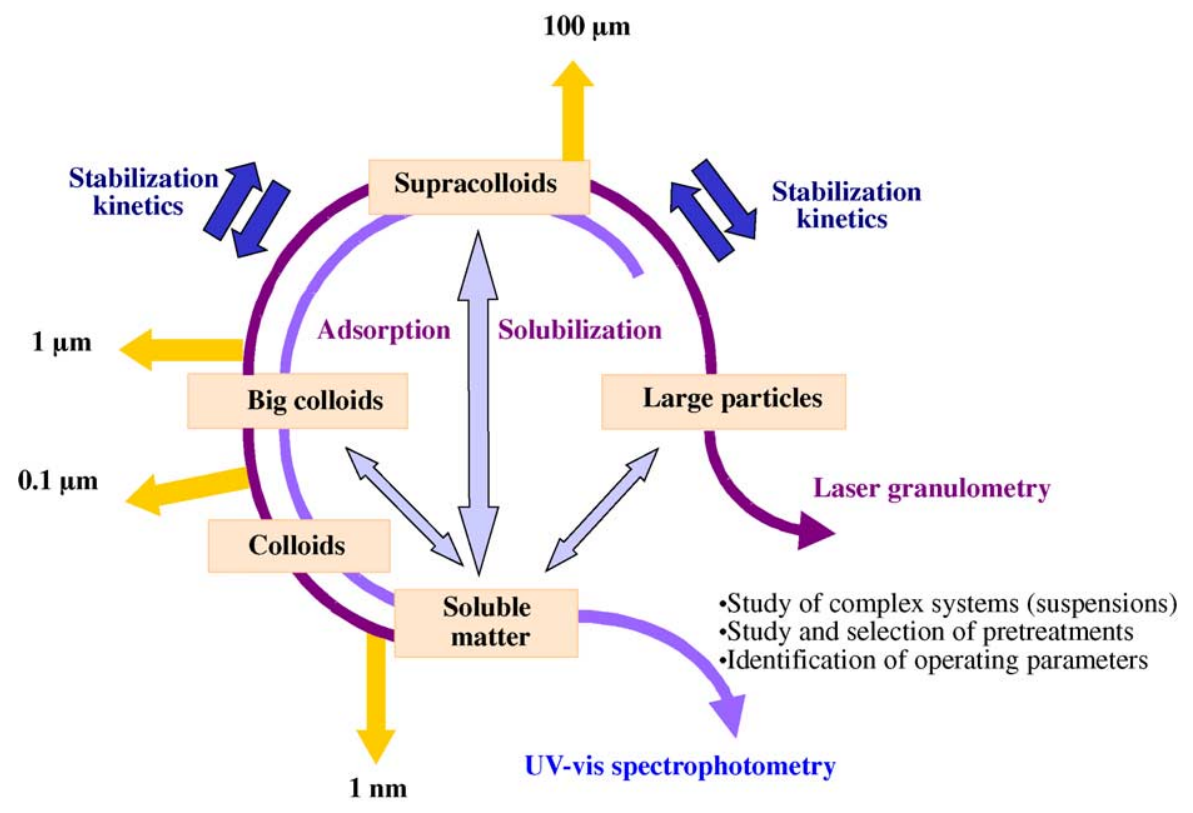

Fig. 1. Scale of analysis and coupling of laser granulometry and UV-vis spectrophotometry.

methods [11], no research work concerning their extended use to study heterogeneous suspensions in a quantitative purpose has been carried out. Furthermore, UV-vis spectrophotometry is often used for the characterization of organic compounds [12], but limitations arise from the fact that physical absorption interfere with chemical one. Consequently, on the one hand, Thomas et al. [13] have proposed reference spectra of suspended solids (TSS) and colloids to model the interferences of UV spectra of wastewater and natural waters. On the other hand, Azéma et al. [14] have shown, in a qualitative way, the influence of granulometric size distribution on the UV responses of organic solids.

In this paper, we propose to study heterogeneous suspensions by coupling the optical methods in a quantitative purpose. The complementary nature of both techniques is mainly based on a complementary scale of analysis, which allows identification and quantification of each component from molecular substances and colloids to millimetric particles (Fig. 1) [15].

The suspensions investigated are mixtures of heterogeneous compounds from the papermaking industries, differing in chemical nature, size and shape: kaolin, calcium carbonate, latex, and optical whitener. The methodology is developed on model mixtures in order to highlight limits and application fields. The final objective is to quantify components in the mixtures using a deconvolution approach with regard to specific features acquired with both optical methods.

\section{Theoretical background}

UV-vis spectrophotometry integrates different combined optical phenomena such as chemical absorption (absorp- tion bands corresponding to structural groups within the molecule) and physical absorption (particles absorption, diffusion, refraction and diffraction). More precisely, when a particle is illuminated by a light beam, light is sent back in all directions of the space: it corresponds to the scattering phenomenon whose three components are the refraction, the reflection and the diffraction [16]. In some cases, the light may be absorbed by particles. These interactions between a light beam and a particle depend mainly on the particle size (diameter $d$ ) and wavelength $(\lambda)$ ratio of the beam of light. In order to clarify the domain of each phenomenon, a size parameter $\alpha$ is generally used [17] and defined as follows (Eq. (1)):

$\alpha=\frac{\pi d}{\lambda}$

where $\lambda$ is the wavelength of the incident light beam (nm) and $d$ is the diameter of the particle (nm).

According to the value of the parameter $\alpha$, and with light sources usually used (UV, visible, near IR), three domains of diffusion are considered.

For $\alpha<0.3$, i.e. for particles smaller than the wavelength, the optical model of the Rayleigh diffusion is used. Particles diffuse light as much forward as backward.

For $\alpha>30$ which corresponds to particles whose size is greater than the wavelength, laws of geometric optics and diffraction are used. In this case, light is diffracted. This means that the diffusion mainly is concentrated in front of the particles.

For $0.3<\alpha<30$, i.e. for particles whose size is close to the wavelength, this intermediate domain corresponds to the validity limit of the last models (diffusion and diffraction), because diffusion is also influenced by reflection, refraction 
Table 1

Origin and concentration of studied samples

\begin{tabular}{|c|c|c|c|c|}
\hline Mineral suspensions & Origin & Main component & $\begin{array}{l}\text { Initial concentrations (for } \\
\text { UV spectra acquisition) }\end{array}$ & $\begin{array}{l}\text { Initial concentrations (for } \\
\text { granulometric distribution } \\
\text { acquisition) }\end{array}$ \\
\hline Carbonate (slurry) & $\begin{array}{l}\text { Les papeteries de Lancey } \\
\text { (France) }\end{array}$ & Calcite & $250 \mathrm{mg} \mathrm{L}^{-1}$ & $35 \mathrm{mg} \mathrm{L}^{-1}$ \\
\hline Kaolin (slurry) & $\begin{array}{l}\text { Les papeteries de Lancey } \\
\text { (FRANCE) }\end{array}$ & Kaolinite & $250 \mathrm{mg} \mathrm{L}^{-1}$ & $125 \mathrm{mg} \mathrm{L}^{-1}$ \\
\hline Talc (slurry) & $\begin{array}{l}\text { Les papeteries de Lancey } \\
\text { (FRANCE) }\end{array}$ & Talc & $10 \mathrm{~g} \mathrm{~L}^{-1}$ & $800 \mathrm{mg} \mathrm{L}^{-1}$ \\
\hline Latex emulsion & Latexia & $\begin{array}{l}\text { Aqueous dispersion of } \\
\text { carboxylated butadiene } \\
\text { styrene co-polymer }\end{array}$ & $207 \mathrm{mg} \mathrm{L}^{-1}$ & $6 \mathrm{mg} \mathrm{L}^{-1}$ \\
\hline $\begin{array}{l}\text { Optical whitener } \\
\text { solution }\end{array}$ & Clariant & Stilbene derivative & $206 \mathrm{mg} \mathrm{L}^{-1}$ & l \\
\hline
\end{tabular}

and absorption phenomena. These ones can be taken into account by the complex theory of Lorenz-Mie [18]. Optical properties of particles are necessary and optical model with real and imaginary parts of refractive index must be used.

Laser granulometry can both integrate classical diffraction measurement (airy disks) and a Polarisation Intensity Differential Scattering (PIDS) system which allows measurements of differential intensities between light beams polarized in vertical and horizontal planes according to three wavelengths of 400,600 , and $900 \mathrm{~nm}$. All scattering data are converted into particle size distributions through the same algorithm using Mie theory. UV-vis spectrophotometry measures light absorption from 200 to $800 \mathrm{~nm}$.

\section{Experimental procedure}

\subsection{Samples}

The methodology is developed on model mixtures of suspensions used in the coating process of Les Papeteries de Lancey (Lancey plant, Isere, France). Two kinds of suspensions are considered: on the one hand, organic suspensions and solutions coming from papermaking process additives (i.e. latex and optical whitener) and on the other hand, slurries of mineral suspensions.

The slurry formulation may contain additives differing in chemical nature and properties. Table 1 gives the origin of the product, information about main components and the initial concentration of samples for UV spectra and granulometric distribution acquisitions. Table 2 presents some properties of the studied minerals (shape, shape factor and density) $[19,20]$.
Table 2

Properties of studied slurries (adapted from [19,20])

\begin{tabular}{llll}
\hline Mineral suspensions & Shape & Shape factor $^{\mathrm{a}}$ & Density \\
\hline Carbonate (slurry) & Rhombus & $1-7$ & 2.7 \\
Kaolin (slurry) & Hexagonal plaques & $1-2$ & 2.6 \\
Talc (slurry) & Flakes & $1-2$ & $2.6-2.8$ \\
\hline
\end{tabular}

${ }^{a}$ Ratio between length and central width (determined from microscopic observations).

Table 3

$\mathrm{pH}$, ionic conductivity, acid and alkaline content of dilution solution

\begin{tabular}{lll}
\hline & Type of solution \\
\cline { 2 - 3 } & Acidic & De-mineralized \\
\hline Acetic acid $(\mathrm{mol} / \mathrm{L})$ & $6.6 \times 10^{-6}$ & 6.5 \\
Initial $\mathrm{pH}$ value & 3.2 & 0.005 \\
Initial conductivity $(\mathrm{mS} / \mathrm{cm})$ & 0.060 & \\
\hline
\end{tabular}

For all experiments, slurries were diluted and mixed with a magnetic stirrer. For UV-vis spectrophotometry experiments, samples were diluted in demineralised water. For granulometry experiments, $\mathrm{pH}$ of dilution water was adjusted before addition to mineral slurries, according to the conditions given in Table 3. Sample dilution was fixed so that the obstruction rate of the laser was kept constant.

\subsection{Methods}

\subsubsection{Fractionation procedure}

For the acquisition of spectra of heterogeneous fractions, the experimental procedure used is described in Fig. 2. Total suspended solids (TSS) are separated by filtering using glass fiber filters (approx. 1.2 $\mu \mathrm{m}$ ). Colloids are separated from

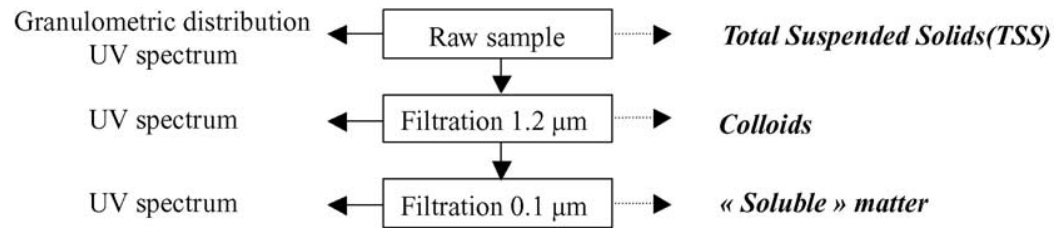

Fig. 2. Fractionation procedure. 
"soluble" matter by cross-flow microfiltration $(0.1 \mu \mathrm{m})$ on acetate membrane.

\subsubsection{Spectra acquisition}

Measurements of particle size distribution were performed using a LS 230 Beckman-Coulter laser granulometer. The volume of the analysis cell is $125 \mathrm{~mL}$. The incident light is transmitted through the circulating suspension.

For mineral suspensions, the small size of particles caused diffusion and reflection phenomena that have to be taken into account. This was performed using the complex theory of Lorentz-Mie. The same optical model (i.e. a refractive index of particles composed of a real part and an imaginary one which corresponds to absorption) must be selected, for all colloidal suspensions, to ensure similar interpretations of scattering phenomenon that occur with particles as raw materials and as components of mixtures. This optical model allows the dimensional scale of validity for scattering pattern interpretation, using a PIDS system, to be extended. In this model, particles are assumed to be spherical, which allows granulometric distributions to be calculated in term of volume percentage. According to previous studies [20,21], the following optical model is chosen $n=1.65+0.01 i$. It has been selected by comparison with data from centrifugation sedimentation analysis based on stocks law (HORIBA Multisize Capa 400) in order to avoid result differential that can occur as a function of particle shapes [5,6].

For UV spectra acquisition, the spectrophotometer used was an Anthelie Light (Secomam) of $2 \mathrm{~nm}$ bandwidth, with a quartz cell of $10 \mathrm{~mm}$ pathlength. The selected speed $\left(1800 \mathrm{~nm} \mathrm{mn}^{-1}\right.$ ) was chosen with respect to the presence of dispersed components in samples.

\subsubsection{Data exploitation}

3.2.3.1. UV spectra. The first method of exploitation of $\mathrm{UV}$-vis spectra is the difference of spectra, corresponding to the difference between the absorbance values for each wavelength [22]. It is thus possible to visualise the spectra of different fractions of one sample. For instance, the spectrum of suspended solids corresponds to the spectrum of the raw sample minus this of the sample filtered at $1.2 \mu \mathrm{m}$, with the following Eq. (2) for each wavelength:

$\operatorname{ABS}_{\mathrm{TSS}}(\lambda)=\operatorname{ABS}_{\text {raw }}(\lambda)-\operatorname{ABS}_{\text {filtered }}(\lambda)$

with $\operatorname{ABS}_{\text {raw }}(\lambda)>\operatorname{ABS}_{\text {filtered }}(\lambda)$

where $\operatorname{ABS}(\lambda)$ is the absorbance value of the considered spectrum for a given wavelength $\lambda$.

The second one is the deconvolution method developed by Thomas et al. [13]. It assumes that each spectrum may be considered as a linear combination of a $p$ reduced number of particular spectra, which are named as reference spectra. These spectra are either spectra of specific compounds or global spectra (colloids and suspended solids). They are selected in a deterministic way from the compounds which may be found in the kind of sample to be analyzed and automatically among the spectra of a particular set of samples. More precisely, this selection is made between different spectra which allow to take into account the effect of the main interferences. From the mathematical point of view, the coefficients of the linear combination are calculated from a system based in the following Eq. (3) established for each wavelength:

$A_{\lambda_{j}}^{\mathrm{u}}=\sum_{i=1}^{p} a_{i} A_{\lambda_{j}}^{\mathrm{ref}_{i}}+r_{j}$

where $A^{\mathrm{u}}$ and $A^{\text {ref }}$ are respectively the absorbance values of the sample spectrum and of the reference one, for a given wavelength $\lambda_{i}, a_{i}$ the coefficient of reference spectra contribution for the explanation of the sample spectrum, and $r_{j}$ the error value.

3.2.3.2. Granulometric distribution. Concerning the granulometric distribution of the studied heterogeneous media, even if some deconvolution softwares are available, limitations arises from the fact that suitable deconvolution parameters have to be selected (modes, full width at half maximum) in order to obtain a convergent solution. The method used has been developed for this study. It is a convolution approach using Matlab software. Reference granulometric distributions are introduced in a quadratic equation method. The contribution coefficients $a_{i}$ were computed as follows (Eq. (4)):

$S=\sum_{i=1}^{p} a_{i} \mathrm{SR}_{i} \pm r$

$S$ is the granulometric spectrum of a sample, $\mathrm{SR}_{i}$ the reference spectra (pure products), $a_{i}$ the contribution coefficient of the $i$ th reference spectrum and $r$ is the restitution difference between real and restituted spectrum.

The reference spectra correspond to the raw materials used. The relevance of the method depends on granulometric properties of the components in the mixture and the possible interaction phenomena between particles. Previously to spectrum acquisition, experimental conditions had to be investigated to ensure that a valuable deconvolution is performed. This study was carried out on different composite samples.

Only representative results are presented in this paper.

\section{Results and discussion}

\subsection{Quantification of colloidal and organic components in mixture with mineral particles using $U V$-vis spectrophotometry}

In order to quantify the raw materials in the model mixtures, a deconvolution from 200 to $600 \mathrm{~nm}$ made up of the 4 spectra for each raw material (Fig. 3), was applied to the mixtures. The UV-vis spectrum of a solution of optical whitener, mainly in soluble form, exhibits four peaks at 205, 236, 277 and $350 \mathrm{~nm}$ due to chemical absorption. The latex suspen- 


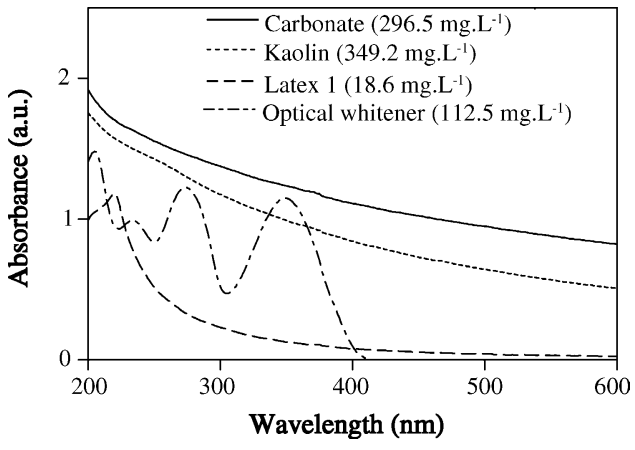

Fig. 3. Reference spectra.

sion spectrum results from the combination of chemical and physical absorption, the peak at $220 \mathrm{~nm}$ is characteristic of the presence of styrenic groups and the residual absorbance at $350 \mathrm{~nm}$ is due to the diffusion of the light by particles. Indeed, fraction spectrum shows that the latex emulsion is mainly colloidal. Besides, measurements by laser granulometry showed that latex suspension presents a monodisperse granulometric distribution with a mode at $0.2 \mu \mathrm{m}$.

Table 4 compares real and estimated concentrations by the deconvolution method of four model mixtures. Optical whitener and latex were always quantified satisfactorily (relative error lower than $10 \%$ of absolute content). Moreover, the method did not allow quantification of the mineral particles to be achieved because of the linear relation existing between the carbonate and kaolin spectra, related to physical absorption. As a matter of fact, UV-vis spectra of mineral particles result only from combination of optical phenomena function of particle size. Kaolin fraction spectra are presented in Fig. 4. The same kind of spectrum shapes were observed as for carbonate and talc suspensions. Fractionations allow to isolate responses of granulometric fractions in TSS and colloid size ranges [23,24].

Table 4

Comparison between real and estimated concentration of components in model mixtures using UV-vis spectrophotometry

\begin{tabular}{|c|c|c|c|c|}
\hline \multirow[t]{2}{*}{ Concentration $\left(\mathrm{mg} \mathrm{L}^{-1}\right)$} & \multicolumn{4}{|l|}{ Mixture } \\
\hline & 1 & 2 & 3 & 4 \\
\hline \multicolumn{5}{|l|}{ Optical Whitener } \\
\hline Real & 10.76 & 14.24 & 16.54 & 1.47 \\
\hline Estimated & 11.43 & 14.54 & 16.92 & 1.59 \\
\hline Error $(\%)$ & 6 & 2 & 2 & 8 \\
\hline \multicolumn{5}{|l|}{ Latex } \\
\hline Real & 23.86 & 21.04 & 17.33 & 4.44 \\
\hline Estimated & 22.16 & 20.79 & 16.91 & 4.80 \\
\hline Error $(\%)$ & 7 & 1 & 2 & 8 \\
\hline \multicolumn{5}{|l|}{ Kaolin } \\
\hline Real & 131.17 & 5.16 & 89.61 & 0.44 \\
\hline Estimated & 71.73 & 0 & 35.15 & 7.0 \\
\hline Error $(\%)$ & 45.3 & I & 60.8 & 1490.9 \\
\hline \multicolumn{5}{|l|}{ Carbonate } \\
\hline Real & 14.6 & 53.16 & 86.15 & 33.28 \\
\hline Estimated & 52.63 & 54.57 & 88.07 & 20.02 \\
\hline Error (\%) & 260.5 & 2.7 & 2.2 & 39.8 \\
\hline
\end{tabular}

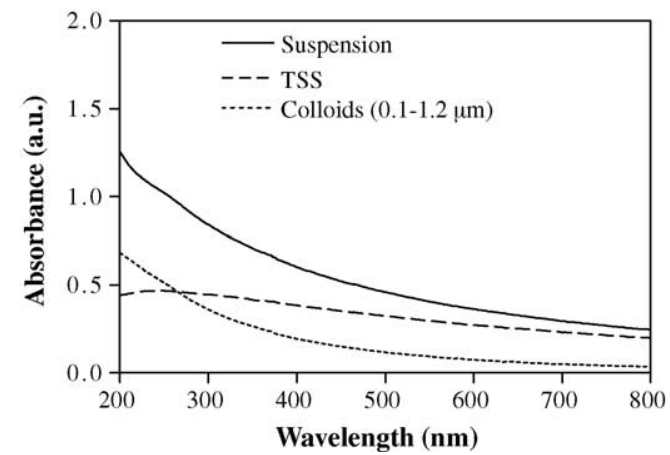

Fig. 4. UV-spectrum of diluted kaolin slurry.

For TSS $(>1.2 \mu \mathrm{m})$, the diffusion domains are both Mie and diffraction ones. Diffusion is characterised by UV-vis spectra with absorbance values slightly dependent on wavelength (diffraction and Mie/diffraction domain) which are almost independent on the wavelength.

For colloids, the diffusion domain is the Mie one. UV-vis responses depend strongly on wavelength. A linear relation between absorbance values and the reciprocal wavelength has been proposed to model the UV response of colloids [24].

Consequently, the mathematical dependence of the two spectra (Fig. 5) does not allow the quantification of mineral particles.

In conclusion, UV-vis spectrophotometry leads to the quantification of the organic compounds which present specific UV-vis responses in model mixtures. The lower limits of quantification are $1 \mathrm{mg} \mathrm{L}^{-1}$ and $0.3 \mathrm{~g} \mathrm{~L}^{-1}$ for the optical whitener and the latex, respectively. Concerning the quantification of mineral particles, laser granulometry is required since no relevant results could be obtained, because of the mathematical dependence of the UV spectra.

\subsection{Semi-quantification of binary mixtures of carbonate and kaolin using laser granulometry}

Laser-granulometry was at first used to determine the kaolin and carbonate percentages in mixture.

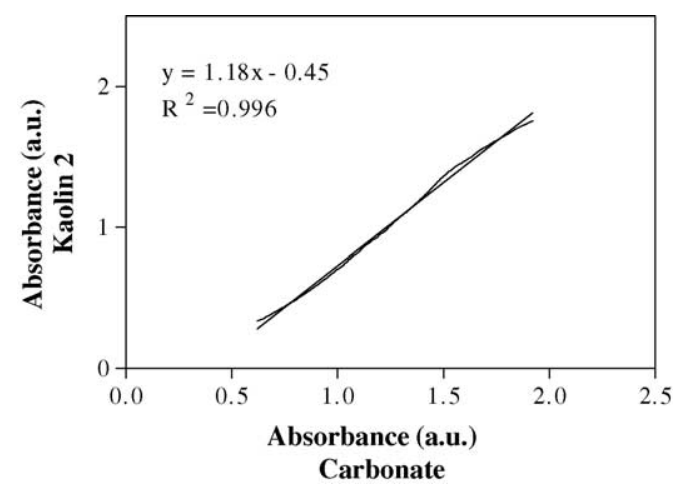

Fig. 5. Absorbance of a suspension of kaolin $\left(349.5 \mathrm{mg} \mathrm{L}^{-1}\right)$ as a function of the absorbance of a carbonate suspension $\left(296.5 \mathrm{mg} \mathrm{L}^{-1}\right)$. 
Table 5

Comparison between real and restored mineral percentage using laser granulometry

\begin{tabular}{lllllc}
\hline $\mathrm{pH}$ & \multicolumn{2}{l}{ Kaolin $($ vol. $\%)$} & & \multicolumn{2}{l}{ Carbonate (vol.\%) } \\
\cline { 2 - 3 } \cline { 6 - 6 } & Real & Restitued & & Real & Restitued \\
\hline Acidic & 43.5 & 91.3 & & 56.5 & 8.7 \\
De-mineralised & 64.1 & 62.3 & & 35.9 & 37.7 \\
\hline
\end{tabular}

The effect of $\mathrm{pH}$ of dilution water was investigated to validate the quantification of each component in mixture. $\mathrm{pH}$ is known to be a main parameter acting on phase transfers in mineral suspension. In kaolin suspensions, particle interactions can be divided into components corresponding to the edge and basal surfaces. Depending on the $\mathrm{pH}$, different types of interactions can occur and lead to different modes of agglomeration [25,26]: basal-basal, edge-basal, and edge-edge. In carbonate suspensions, dissolution-precipitation can occur as a function of $\mathrm{pH}$ [27]. For calcite, kinetic equilibrium is reached at $\mathrm{pH} 6.5$, so that no change is observable for this value over time, even though dissolution and precipitation occur continuously [28].

In this study, quantification was performed with reference spectra acquired on slurries diluted with the solutions described in Table 3. The measurement is carried out after the suspension had circulated in the analysis cell for $1 \mathrm{~h}$. The same experimental conditions were applied to slurries in the mixtures.

Results in Table 5 clearly show that kaolin tends to be overestimated at the expense of carbonate at acidic $\mathrm{pH}$. This may be explained by the carbonate dissolving and confirmed by the $\mathrm{pH}$ increase as a function of time. In consequence, a diminution of a single component content could not be detected because of the volume normalization to $100 \%$ in granulometric analysis. But in a mixture with a stable component, in this case kaolin, dissolution of carbonate was enhanced and led to an increase in the relative error. In demineralized water, less detrimental to particle stability, the relative error for carbonate was the lowest and about $5 \%$.

Even though no direct relationship was established, results showed that quantification error could be related to phase transfers either between particles and soluble matter (dissolution/precipitation), as it is the case in this study, or between particles themselves (agglomeration/dispersion). During analysis, suspension concentrations range in diluted regime and no significant agglomeration phenomena are observed on granulometric distributions.

The sample circulation time before spectrum acquisition was also investigated as another analysis parameter: two waiting times before analysis were tested $(5 \mathrm{~min}$ and $1 \mathrm{~h}$ ). The relative error in de-mineralized water was the lowest after 5 min of sample circulation. In these conditions, relative error is $1.5 \%$ for the carbonate percentage.

Finally, semi-quantification using laser-granulometry was considered to be accurate for dilution in de-mineralized water, with a waiting time before analysis of $5 \mathrm{~min}$.

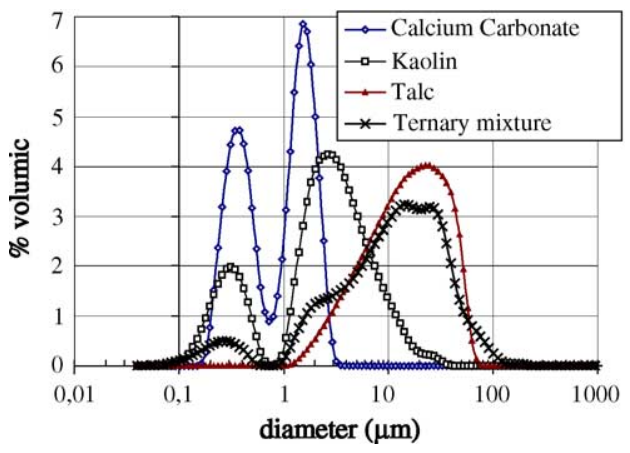

Fig. 6. Reference granulometric distributions of kaolin, calcium carbonate and talc and a ternary mixture spectrum $(\operatorname{talc}(\%)=73)$.

\subsection{Semi-quantification of binary and ternary mixtures of carbonate, kaolin and talc using laser granulometry}

The deconvolution method was applied on talc slurry in binary and ternary mixtures with kaolin and calcium carbonate slurries. As we can, observed in Fig. 6, the talc dimensions range from 1 to $85 \mu \mathrm{m}$.

In a general manner, restituted talc percentages in binary and ternary mixtures (Fig. 7) increase with the real talc percentage increase. However, the absolute error can be very different according to the mixture considered. It is more important for small percentages of talc. A talc overestimation tendency can be featured, suggesting that errors are not ascribed to mass transfers in this case but due to spectra normalization. Indeed, the larger size of talc particles compared to calcium carbonate and kaolin ones (respectively lower than 3 and $20 \mu \mathrm{m}$ ) implies an error. It can be explained the fact that few talc particles occupy an important volume. Thus, a correction factor as a function of granulometric distributions ranges could be considered, and it could be experimentally established as a function of granulometric distributions ranges by using mixtures of model size particles and an ACP regression. But it was not the object of this work.

\subsection{Quantification of all components in suspension by coupling optical methods}

We propose to apply the coupling of optical method according to the previous methodology in order to quantify components of a industrial sample from a roller coating step of a papermaking process: a coating slip. Roller coating consists in applying the coating slip on paper surface to provide specific characteristics such as brightness, opacity, printability, .... A metal blade allows to remove excessive coating. The coating slip formulation provided by the papermaker is the following:

- $0.5 \%$ of optical whitener;

- $8.5 \%$ of latex;

- $90 \%$ of mineral pigments: $25 \%$ of kaolin and $75 \%$ of carbonate;

- $1 \%$ of unknown organic compounds. 

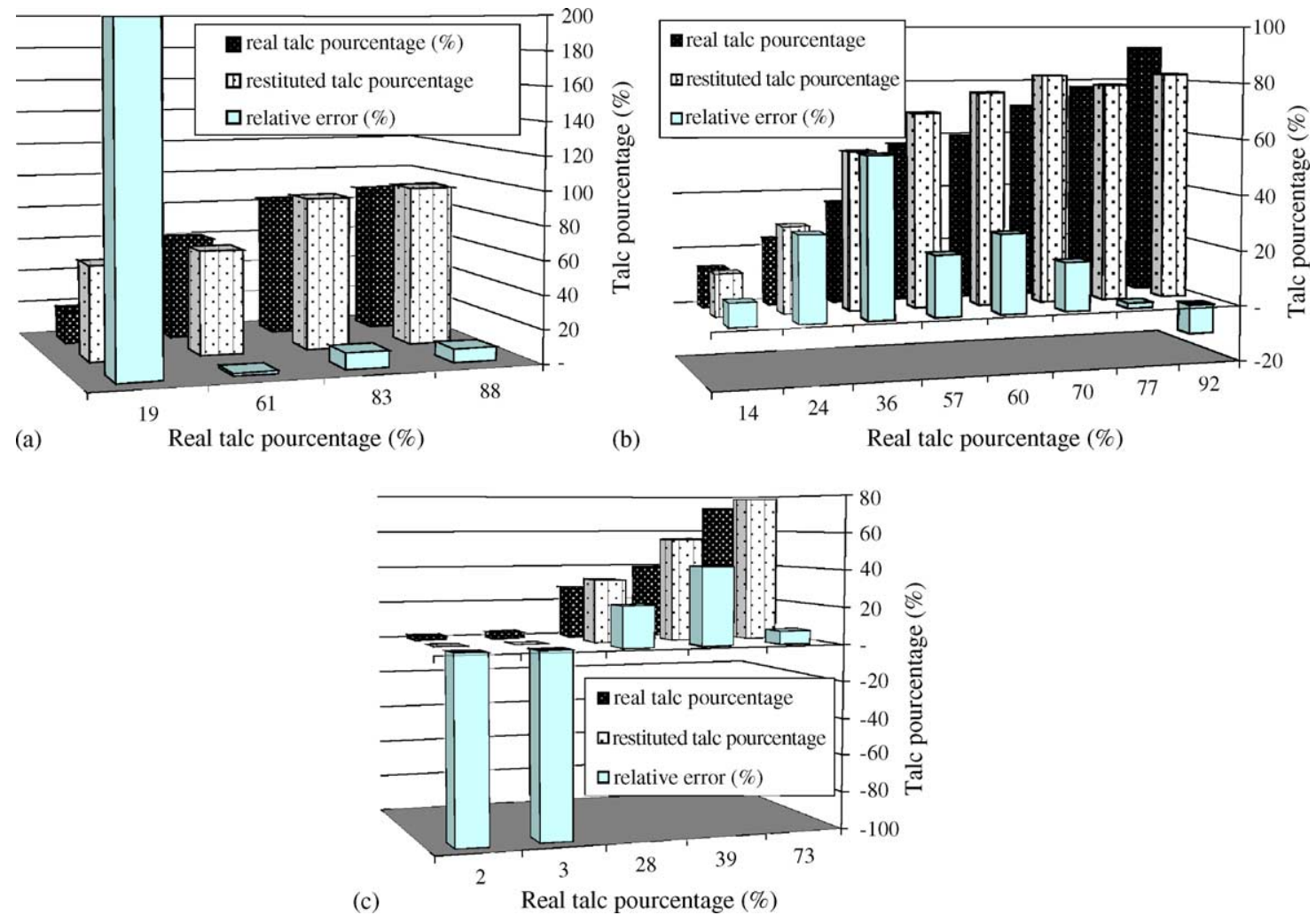

Fig. 7. Real and restituted talc percentages, Absolute error as a function of talc percentage in mixture (a) with calcium carbonate, (b) with kaolin and (c) with both.

Using UV-vis spectrum deconvolution (see Section 3.2.3), a latex content of $10 \%$ was restituted. That can be considered as a valuable approximation in comparison with the exact content (8\%). However, optical whitener content was not well restitued (relative error of about 50\%). As a matter of fact, soluble fraction of the coating slip exhibited a differing spectrum from the raw sample one (Fig. 8). This change may be due to the chemical nature of the optical whitener (stilbene derivatives) which is light sensitive [29]: optical whitener exposure to sunlight causes reversible isomerization and UV-vis spectrum changes as it is showed in Fig. 9. In consequence, the suitable reference spectrum to perform deconvolution can be chosen according to absorbance ratio

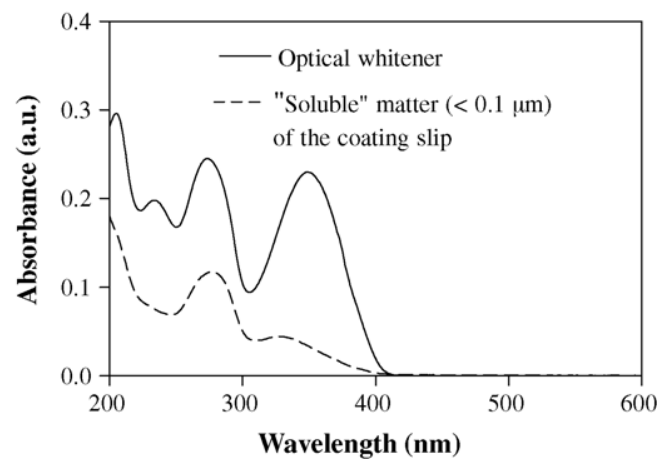

Fig. 8. Comparison of the optical whitener spectra in raw material form and in the coating slip.

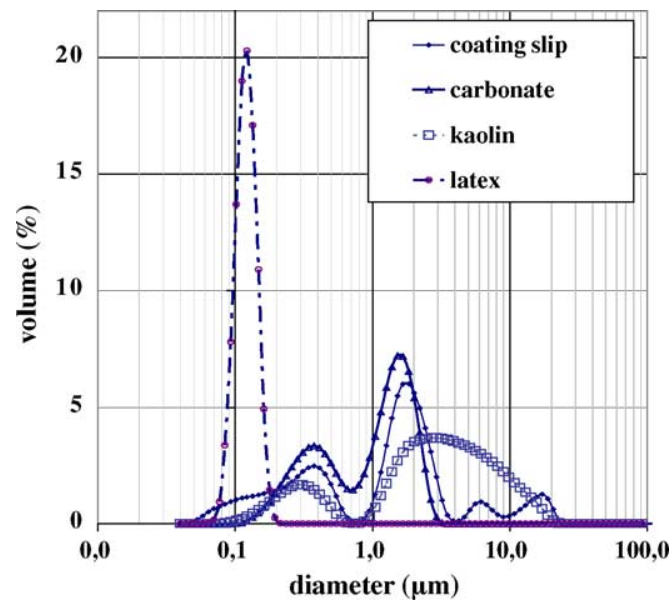

Fig. 9. Reference granulometric distributions used in the deconvolution method.

showed in Table 6. Optical whitener can be then satisfactorily quantified with a relative error of $9 \%$.

As described in Section 4.1, laser granulometry was required to determine the proportion of mineral pigments.

Table 6

Absorbance ratio of UV-vis spectra in the cases of optical whitener in raw material form or after a daylight exposure time of $6 \mathrm{~h}$ in solution

Optical whitener in raw material form $(A(276 \mathrm{~nm}) / A(350 \mathrm{~nm})) \quad 2.84$ Optical whitener exposed to light $(A(276 \mathrm{~nm}) / A(328 \mathrm{~nm}))$ 


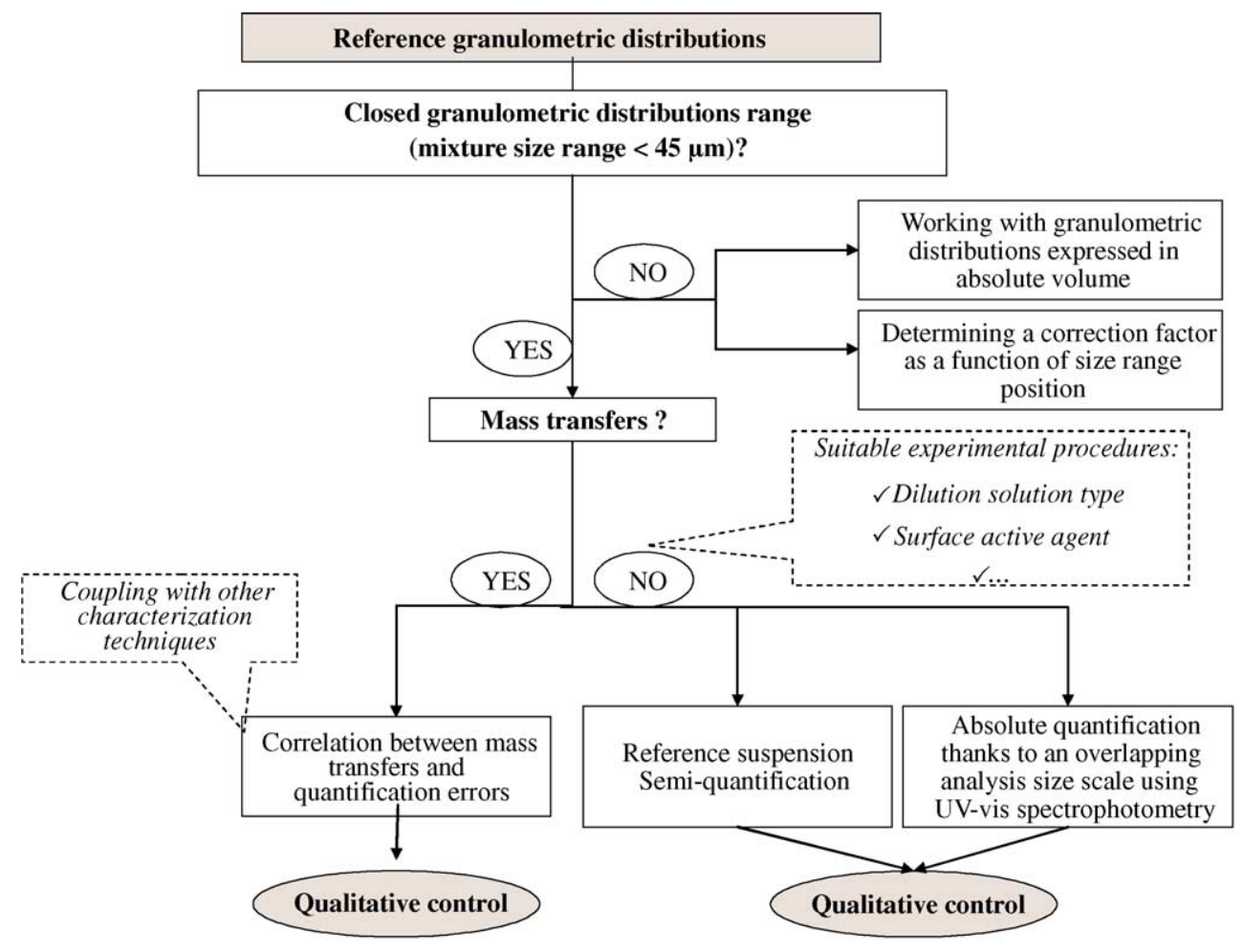

Fig. 10. Methodology to study heterogeneous mixtures using reference spectra deconvolution.

Latex has also been considered for deconvolution. The spectra presented in Fig. 9 were used in the deconvolution method and were obtained according to the experimental conditions described in Section 3.2.2. The following linear Eq. (5) was restituted:

$S=0.07$ latex +0.71 carbonate +0.22 kaolin

According to the latex/carbonate and latex/kaolin ratios obtained from laser granulometry, on the one hand, and absolute latex content provided by UV-vis spectrophotometry, on the other hand, the absolute content of each mineral pigment can be deduced.

Then, the coupling allows the following content of each component to be restituted:

- $0.85 \%$ of optical whitener;

- $6.95 \%$ of latex;

- $92.2 \%$ of mineral pigments $(21.7 \%$ of kaolin and $70.4 \%$ of carbonate).

The method accuracy strongly depends on the restituted latex content when using UV-vis spectrophotometry.

All these results lead us to propose in Fig. 10 a summarizing diagram of the methodology. A limit value of $45 \mu \mathrm{m}$ for quantification using deconvolution method to be accurate can be proposed. It corresponds to the maximal diameter of granulometric distributions.

\section{Conclusions: limits and prospect}

This study shows the potential of coupling laser granulometry and UV-vis spectrophotometry in order to quantify particles, dissolved and colloidal matter in suspensions. At first, it proved that quantification efficiency is related to the stability of raw materials in the mixture. It means that reference spectra have to be obtained on individual raw materials. Under these conditions, the quantification of mineral particles, latex and optical whitener can be successfully performed due to an overlapping range of analysis in colloid domain. Another limitation raised from the fact that semi-quantification of mineral particles using normalized granulometric distribution is more reliable in a close particle size range.

This methodology could also be applied to the monitoring of mass transfer phenomena in many disperse media (such as dissolution, agglomeration and adsorption) in a qualitative manner to investigate suspension stability. In a process involving dimensional parameters or the stability of disperse solids, this methodology could also be used for process control purposes.

\section{Acknowledgements}

This methodology was applied for beneficial purposes (raw materials recycling, water recirculation, internal flow management and optimization) in the framework of the RECYMEAU project (RITEAU network). The authors are 
grateful to the French Ministry of Research for financial support and to the scientific and industrial partners of the Ecole des Mines d'Alès: Centre Technique du Papier (CTP), Ecole Française de Papeterie et des Arts Graphiques (EFPG), Les Papeteries de Lancey, Orelis.

\section{References}

[1] T.G. Metzger, The Rheology Handbook, for Users of Rotational and Oscillatory Rheometers, Vincentz Verlag, Hannover, 2002.

[2] C. Bordes, F. Garcia, P. Snabre, C. Frances, On line characterization pf particle size during an ultrafine wet grinding process, Powder Technol. 128 (2002) 218-228.

[3] E. Kissa, Dispersions Characterization, Testing and Measurement, Marcel Dekker, New York, 1999, p. 708.

[4] M. Naito, O. Hayakawa, K. Nakahira, H. Mori, J. Tsubaki, Effect of particle shape on the particle size distribution measured with commercial equipment, Powder Technol. 100 (1998) 52-60.

[5] J.W. Novak, J.R. Thompson, Extending the use of particle sizing instrumentation to calculate particle shape factors, Powder Technol. 45 (1985) 159-167.

[6] S. Lohmander, Aspect ratio of pigment particles determined by different methods, Nordic Pulp Pap. Res. J. 3 (2000) 221-230.

[7] A. Jones, D. Yuong, J. Taylo, B. Kell, J.J. Rowland, Quantification of microbial productivity via multi-angle light scattering and supervised learning, from: http://www.aber.ac.uk/ abcwww/light.html (2001).

[8] C. Selomulya, R. Amal, G. Bushell, T.D. Waite, Evidence of shear rate dependence on restructuring and breakup of latex aggregates, $\mathrm{J}$. Colloid Interface Sci. 236 (2001) 67-77.

[9] H. Kleizen, A.B. de Putter, M. van der Beek, S.J. Huynink, Particle concentration, size and turbidity, Filtr. Sep. 32 (1995) 897-901.

[10] L.M. Gugliotta, J.R. Vega, G.R. Meira, Latex particle size distribution by dynamic light scattering: computer evaluation of two alternative calculation paths, J. Colloid Interface Sci. 228 (2000) $14-17$.

[11] A.R. Jones, Light scattering for particle characterization, Prog. Energy Combust. Sci. 25 (1999) 1-53.

[12] J.M. Fu, Y. Li, J.L. Guo, Optical behavior of organic pigments in aqueous dispersions and its application, J. Colloid Interface Sci. 202 (1998) 450-445.

[13] O. Thomas, F. Théraulaz, M. Domeizel, C. Massiani, UV spectral deconvolution: a valuable tool for wastewater quality determination, Environ. Technol. 14 (12) (1993) 1187-1192.
[14] N. Azéma, M.F. Pouet, C. Berho, O. Thomas, Wastewater suspended solids study by optical methods, Colloids Surf. A Physicochem. Eng. Aspects 204 (2002) 131-140.

[15] S. Bayle, C. Berho, N. Azéma, M.F. Pouet, J.M. Lopez-Cuesta, O. Thomas, Caractérisation de suspensions papetières, poster laureate of a price Recherche-Innovation ADEME-Energies and Measures, in: POLLUTEC-Lyon, ADEME Editions, 2002.

[16] A. Keitz, D. Boulaud, Mesures et contrôle. Granulométrie des particules en mouvement et des aérosols, Techniques de l'ngénieur, Paris R2 (360) (1995) 2-4.

[17] M. Kerker, The Scattering of Light and other Electromagnetic Radiation, Academic Press, New York, 1969.

[18] M. Xu, R.R. Alfano, More on patterns in Mie scattering, Opt. Commun. 226 (2003) $1-5$

[19] S. Caillere, S. Henin, M. Rautureau, Minéralogie des argiles - T1: structure et propriétés physico-chimiques, Paris, INRA et Masson 2 (1982).

[20] S. Bayle, Etude de suspensions hétérogènes pour le contrôle d'un procédé papetier Dimensions et propriétés optiques de la matière: des paramètres discriminants, Ph.D. Thesis, Université Montpellier II, 2004.

[21] Norme Iso/TC24/SC 4 N 114, Particle size analysis, Guide to Laser Diffraction Methods.

[22] S. Vaillant, M.F. Pouet, O. Thomas, Basic handling of UV spectra for urban water quality monitoring, Urban Water 4 (2002) 273-281.

[23] C. Berho, Caractérisation de fractions hétérogènes par méthodes optiques au cours de procédés de fabrication, Application aux suspensions papetières et vinicoles. Ph.D. Thesis, Université de Pau et des Pays de l'Adour, 2003.

[24] C. Berho, M.F. Pouet, S. Bayle, N. Azéma, O. Thomas, Study of UV-vis responses of mineral suspensions in water, Colloids Surf. A Physicochem. Eng. Aspects 248 (2004) 9-16.

[25] S.B. Johnson, G.V. Franks, P.J. Scales, D.V. Boger, T.W. Healy, et al., Surface chemistry-rheology relationships in concentrated mineral suspensions, Int. J. Mineral Process. 58 (2000) 267-304.

[26] J.C. Austin, R.E. Challis, The effects of flocculation on the propagation of ultrasound in dilute kaolin slurries, J. Colloid Interface Sci. 206 (1998) 146-157.

[27] B. Hamrouni, M. Dhahbi, Calco-carbonic equilibrium calculation, Desalination 152 (2003) 167-174.

[28] J.W. Morse, R.S. Arvidson, The dissolution kinetics of major sedimentary carbonate minerals, Earth-Sci. Rev. 58 (2000) 51-84.

[29] T. Poiger, Behavior and fate of detergent-derived fluorescent whitening agents in sewage treatment. Ph.D. Thesis, Swiss Federal Institute of Technology, 1964. 